\title{
Biologic Entity Identifier
}

National Cancer Institute

\section{Source}

National Cancer Institute. Biologic Entity Identifier. NCI Thesaurus. Code C93398.

The unique identification of a biologic entity in a specified context. 